\title{
Inhibition of Extracellular Enzymes Exposed to Cyanopeptides
}

\author{
Christine M. Egliab, Regiane S. Natumib, Martin R. Jones ${ }^{b}$, and Elisabeth M.-L. Janssenb
}

\begin{abstract}
Harmful cyanobacterial blooms in freshwater ecosystems produce bioactive secondary metabolites including cyanopeptides that pose ecological and human health risks. Only adverse effects of one class of cyanopeptides, microcystins, have been studied extensively and have consequently been included in water quality assessments. Inhibition is a commonly observed effect for enzymes exposed to cyanopeptides and has mostly been investigated for human biologically relevant model enzymes. Here, we investigated the inhibition of ubiquitous aquatic enzymes by cyanobacterial metabolites. Hydrolytic enzymes are utilized in the metabolism of aquatic organisms and extracellularly by heterotrophic bacteria to obtain assimilable substrates. The ubiquitous occurrence of hydrolytic enzymes leads to the co-occurrence with cyanopeptides especially during cyanobacterial blooms. Bacterial leucine aminopeptidase and alkaline phosphatase were exposed to cyanopeptide extracts of different cyanobacterial strains (Microcystis aeruginosa wild type and microcystin-free mutant, Planktothrix rubescens) and purified cyanopeptides. We observed inhibition of aminopeptidase and phosphatase upon exposure, especially to the apolar fractions of the cyanobacterial extracts. Exposure to the dominant cyanopeptides in these extracts confirmed that purified microcystins, aerucyclamide A and cyanopeptolin A inhibit the aminopeptidase in the low $\mathrm{mg} \mathrm{L}^{-1}$ range while the phosphatase was less affected. Inhibition of aquatic enzymes can reduce the turnover of nutrients and carbon substrates and may also impair metabolic functions of grazing organisms.
\end{abstract}

Keywords: Aquatic enzymes · Biogeochemical cycling · Cyanobacteria · Harmful algae bloom · Microbial loop

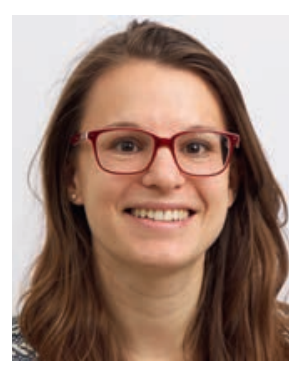

Christine Egli received her BSc degree in Environmental Sciences at ETH Zurich (2012) and her MSc degree in Environmental Sciences with focus on biogeochemistry and pollutant dynamics at ETH Zurich (2015). She conducted her doctoral studies in Environmental Chemistry at ETH Zurich and at the Swiss Federal Institute of Aquatic Science and Technology (Eawag) from 2015 to 2019. Her research focusses on the inactivation processes of aquatic extracellular enzymes by photooxidation and other inhibitors using proteomics techniques and enzyme activity assays.

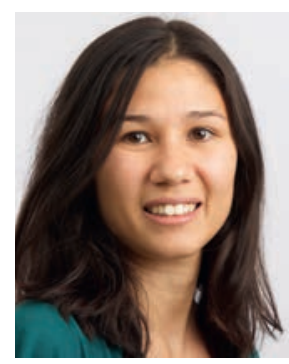

Regiane Natumi received her BSc degree in Environmental Chemistry at University of São Paulo (2013) and her MSc degree in Environmental Sciences at University Trier (2016). Since 2017, she continues with her doctoral studies in Environmental Chemistry at the Swiss Federal Institute of Aquatic Science and Technology (Eawag) enrolled at ETH Zurich. Her research focuses on the production dynamics and persistence of cyanobacterial bioactive metabolites.

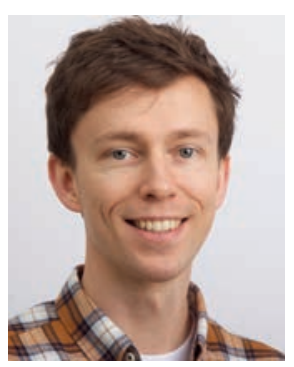

Martin Jones received his $\mathrm{PhD}$ in 2017 from the University of Birmingham, U.K., where his research focused on developing an analytical and bioinformatics workflow to support the deep annotation of metabolomes. Since 2019, he continues with post-doctoral research in Environmental Chemistry and Toxicology at the Swiss Federal Institute of Aquatic Science and Technology (Eawag). His current research focuses on developing analytical techniques and data analysis workflows to support the detection and annotation of emerging cyanobacterial metabolites, in addition to testing their potential toxicological effects.

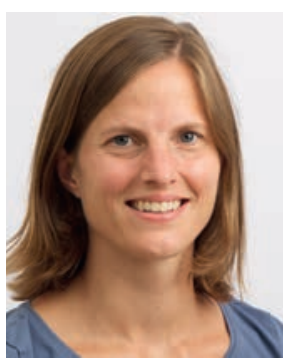

Elisabeth Janssen received her $\mathrm{PhD}$ in 2010 from Stanford University in Environmental Engineering and Sciences before conducting post-doctoral research at the Natural History Museum in London (UK, 2011) and in Environmental Chemistry at ETH Zurich (2012-2015) where she continued as a senior researcher in photochemistry. Since 2016, she is a research group leader in the Environmental Chemistry department at the Swiss Federal Institute of Aquatic Science and Technology (Eawag) focusing on occurrence and fate processes of micropollutants and biomolecules in aquatic systems. 


\section{Introduction}

Cyanopeptides are non-ribosomal oligopeptides and metabolic products of cyanobacteria, which can occur at elevated concentrations during cyanobacterial blooms. Microcystins, one class of cyanopeptides, have been studied most extensively after they had been linked to human intoxication events in the 1990s. Recent studies demonstrate that other emerging cyanopeptides including cyanopeptolins, anabaenopeptins, aerucyclamides, aeruginosines and microginins are often co-produced with microcystins and at similar concentrations. ${ }^{[1-3]}$ While these cyanopeptides have received much less attention, several studies indicate that toxicity from cyanobacteria can go beyond what would be expected from microcystins alone. Consequently, harmful cyanobacterial blooms can pose ecological and human health risks but a risk assessment for many secondary metabolites does not exist to date.

Exposure of aquatic organisms to the complex extracts of cyanobacterial bloom material consisting of either Microcystis spp. or Planktothrix agardhii, has been shown to elicit acute toxicological response. ${ }^{[4]}$ Additionally, these studies also demonstrated that exposure to extracts of biomass from Microcystis mutants that cannot produce microcystins showed similar or even stronger adverse effects. Similar results were obtained when Daphnia magna was fed with cyanobacteria and their respective microcystin-free mutants directly. ${ }^{[5]}$ Exposed organisms showed significant lethal effects, indication of stress and influence on reproduction such as reproductive health and inhibition of fecundity. In addition to the direct risk to human health and aquatic organisms, enzyme inhibition is a commonly observed (sub-)lethal effect of cyanopeptides. Microcystins can cross cell membranes via organic anion transport proteins and has been found to inhibit protein phosphatase 1 and $2 \mathrm{~A}$ in the liver at low nanomolar concentrations. ${ }^{[6,7]}$ Other cyanopeptides have been found to inhibit proteases with inhibitory potencies also down to the nanomolar range. For example, some microginins have been shown to inhibit microsomal or cytosolic leucine aminopeptidases, ${ }^{[8,9]}$ anabaenopeptins have substantially lowered carboxypeptidase A activity ${ }^{[9,10]}$ and cyanopeptolins have inhibited various proteases such as chymotrypsin, ${ }^{[11]}$ plasmin and trypsin. ${ }^{[9]}$ An overview with inhibitory concentration ranges for different enzymes and model organisms can be found in a recent review. ${ }^{[4]}$ To date, most studies on enzyme inhibition by cyanopeptides have been conducted with human toxicologicallyrelevant model proteases such as trypsin, human serine protease, leucine aminopeptidase and carboxypeptidases. Enzyme inhibition stands out as one common mode of action of cyanopeptides, which this study focused on. ${ }^{[2,3,12]}$

Enzyme inhibition by cyanobacterial blooms can affect biological communities and the biogeochemical cycling within the ecosystem. When a bloom is forming, fast cell proliferation and nutrient consumption can affect local $\mathrm{pH}$ and dissolved oxygen concentrations. ${ }^{[13]}$ Many cyanobacterial taxa also have the ability to fix atmospheric nitrogen and access otherwise non-bioavailable phosphorus in the sediment, which can substantially affect nitrogen and phosphorus cycles. ${ }^{[14]}$ Given that extracellular enzyme hydrolysis is regarded as the rate-limiting step in organic matter mineralization, extracellular enzymes are important drivers of biogeochemical nutrient and organic matter cycling in aquatic systems. ${ }^{[15]}$ The imposed effect of extracellular enzymes on the biogeochemical cycles depends on their activity, which in turn is highly influenced by interactions with mineral surfaces, organic matter and chemical transformation processes such as photochemical degradation. ${ }^{[16,17]}$ Although cyanobacteria are known to produce extracellular enzymes themselves, ${ }^{[18]}$ the effect of cyanobacterial blooms on extracellular enzyme activity has mainly been associated with enzymes released by associated heterotrophic bacteria. ${ }^{[19]}$ Despite the broadly investigated inhibitory effects of cyanopeptides towards proteases and a protein phosphatase, it remains unknown whether cyanopep- tides inhibit biogeochemically relevant extracellular enzymes that were secreted by other organisms than the blooming cyanobacteria. Here, we not only assessed the inhibition potential of cyanobacterial blooms, we also aimed to identify potential suspect cyanopeptides or peptide classes causing enzyme inhibition. Achieving this objective is challenged by the vast variety of potential cyanopeptides for which current analytical standard materials are not available. To date, hundreds of cyanopeptides have been structurally identified and many are co-produced by a single cyanobacterial species causing a mixture of cyanopeptides in one bloom event. The large variety of cyanopeptides challenges a fast progress towards their risk assessment regarding exposure concentrations and delineating their potential toxic mode of action. Unequivocal analytical identification of a cyanopeptide requires reference standards that are currently not available for emerging cyanopeptides and only for few microcystins. Separation by liquid chromatography and detection by high resolution mass spectrometry is the state-of-the-art analytical method to identify cyanopeptides. In the absence of available standards or bioreagents, the identification of cyanopeptides relies on careful evaluation of the mass spectrometry information and comparison of chromatographic features across positively identified samples and purified bioreagents.

We assessed the inhibition potential of cyanobacterial metabolites on two extracellular enzymes, Escherichia coli alkaline phosphatase and Aeromonas proteolytica leucine aminopeptidase. We exposed the enzymes to biomass extracts of Microcystis aeruginosa, a microcystin-free mutant of the same Microcystis strain and Planktothrix rubescens to determine the inhibitory potencies of cyanopeptide mixtures. We determined concentrations of microcystins and emerging cyanopeptides by liquid chromatography high resolution mass spectrometry. Additionally, we tested purified cyanopeptides (cyanopeptolin A, aerucyclamide $\mathrm{A}$ and various microcystins) to further evaluate the inhibition pattern.

\section{Materials and Methods}

\section{Materials}

Escherichia coli alkaline phosphatase (ECAP, PDB 1ED9, 62.77 units $\mathrm{mg}^{-1}$ protein, $3.25 \mathrm{mg} \mathrm{mL}^{-1}$ in glycine buffer) and Aeromonas proteolytica aminopeptidase (BLAP, PDB 1RTQ, 116.51 units $\mathrm{mg}^{-1}$ ) were purchased from Sigma and kept at $-20^{\circ} \mathrm{C}$ until use. Cyanopeptide materials used for identification and quantification included a microcystin mixture consisting of microcystin-LR (MC-LR), MC-LF, MC-LA, MC-LY, MC-LW, MC-RR, MC-YR, and Nodularin purchased from Enzo Life Sciences, Inc. $\left(>90 \%\right.$ purity, stored in ethanol at $-20{ }^{\circ} \mathrm{C}$ ), aerucyclamide A was purified earlier by Portmann et al..$^{[20]}$ of which we obtained a stock solution stored in dimethyl sulfoxide (DMSO, at $-20{ }^{\circ} \mathrm{C}$; cyanopeptolin A, cyanopeptolin D, anabaenopeptin A, and anabaenopeptin B from Cyano Biotech Inc. ( $>90 \%$ bioreagent, stored in $1 \%$ to $100 \%$ methanol at $-20{ }^{\circ} \mathrm{C}$ ). For the enzymatic activity assays 4-methylumbelliferyl phosphate (MUP), 4-methyl-umbelliferone (MUOH), 7-leucine-7-amido-4-methylcoumarin hydrochloride (LeuC), and 7-amino-4-methylcoumarin (AMC) were obtained from Sigma. Additional materials included: sodium chloride (for molecular biology, $\geq 98 \%$ ), DMSO (for molecular biology), and tris(hydroxylmethyl)-aminomethane (Tris, ACS reagent, $\geq 99.8 \%$ ) by Sigma; and methanol (Fisher Scientific, OPTIMA LC/MS Grade), formic acid (Merck, $\geq 98 \%$ ), ethanol (Merck, ACS ISO Reag. Ph Eur).

\section{Cyanopeptide Extraction and Purification}

Three cyanobacterial strains were batch cultured in modified WC medium:[21] (1) Microcystis aeruginosa PCC7806, (2) a nonmicrocystin producing mutant of the same strain for which the 
mcyD gene has been knocked out, ${ }^{[22]}$ and (3) Planktothrix rubescens SCCAP K-0576. Cultures were grown at $20 \pm 2{ }^{\circ} \mathrm{C}$ and $12 \mu \mathrm{mol}$ photons $\mathrm{m}^{-2} \mathrm{~s}^{-1}$ irradiance with a day-night cycle of $12 \mathrm{~h}$. The biomass was separated from the medium by centrifuging ( $\mathrm{rcf}$ of $\left.5^{\prime} 000 \mathrm{~g}, 10 \mathrm{~min}, 10^{\circ} \mathrm{C}\right)$, frozen at $-80^{\circ} \mathrm{C}$, lyophilized $\left(-80^{\circ} \mathrm{C}\right.$, 3 mbar, $24 \mathrm{~h}$ ) and stored at $-20^{\circ} \mathrm{C}$ until extraction.

Cyanopeptides were extracted from the biomass three times with 70:30\% v/v methanol:nanopure water ( $1 \mathrm{~mL}$ per $50 \mathrm{mg}$ ) under sonication (10 min, sonicator bath). The supernatants of each extraction were removed from the pellet by centrifuging ( $\mathrm{rcf}$ of 5'000 g $10 \mathrm{~min}$ ). Supernatants were combined and the methanol evaporated under a gentle stream of $\mathrm{N}_{2}$ (TurboVap, $0.8 \mathrm{~L} \mathrm{~min}^{-1}$ gas flow, $40{ }^{\circ} \mathrm{C}$ ). The aqueous extract was subjected to solid phase extraction (SPE; Oasis HLB, 3 CC, $60 \mathrm{mg}$ ). SPE cartridges were conditioned using $9 \mathrm{~mL}$ methanol and equilibrated for sample loading using $9 \mathrm{~mL}$ of nanopure water. Samples were then loaded on to the cartridge, followed by washing with 9 $\mathrm{mL}$ nanopure water and then $9 \mathrm{~mL} \mathrm{20 \%} \mathrm{methanol} \mathrm{v/v} \mathrm{(aq.)} \mathrm{to}$ remove the most polar matrix constituents. The next elution with $55: 45 \%$ v/v methanol:nanopure water was collected as the "polar fraction' with the more polar cyanopeptides and subsequent elution with $85: 15 \%$ v/v methanol:nanopure water was collected as the 'apolar fraction' containing the more apolar cyanopeptides. Both SPE fractions were concentrated by vacuum-assisted evaporation (Büchi Syncore, $50{ }^{\circ} \mathrm{C}$ ) to a final aqueous solution, stored at $4{ }^{\circ} \mathrm{C}$ when used the next day or at $-20{ }^{\circ} \mathrm{C}$ for longer storage.

Extract solutions were produced by using different amounts of biomass (210 mg M. aeruginosa, $50 \mathrm{mg}$ Microcystis mutant and $54 \mathrm{mg} P$. rubescens), which needs to be considered when interpreting observed differences in enzyme inhibition.

\section{Inhibition Experiments}

The inhibition of phosphatase and aminopeptidase in the presence of different extracts or single cyanopeptides was assayed at concentrations between $0.1 \mathrm{nM}$ and $50 \mu \mathrm{M}$. The experimental enzyme concentrations were set to an initial activity of $0.835 \mathrm{mU} \mathrm{mL}^{-1}$ for phosphatase and to $0.047 \mathrm{mU} \mathrm{mL}^{-1}$ for aminopeptidase, respectively. Enzymes were dissolved in Tris- $\mathrm{HCl}$ buffer (aq., $10 \mathrm{mM}$, pH 7.5) with an ionic strength of $30 \mathrm{mM}$ adjusted with $\mathrm{NaCl}$. Inhibitor solution was added to enzyme solutions in equal volumetric parts. Tris buffer solution was used for negative controls and additional matrix controls with respective solvent concentrations of methanol or DMSO were included.

The experimental solutions were incubated at $4{ }^{\circ} \mathrm{C}$ for up to $60 \mathrm{~min}$, then the first activity measurement was conducted $(0 \mathrm{~h}$ time point). Solutions were stored in the dark at $4{ }^{\circ} \mathrm{C}$ and the activity was measured again with a second aliquot after $24 \mathrm{~h}$ incubation ( $24 \mathrm{~h}$ time point). All activities are expressed relative to the respective controls in buffer and are corrected for solvent effects by subtracting the inhibition in the controls with solvent matrix of the respective experimental solution (residual solvent ranged between $0.1-0.5$ volume $\%$ ).

\section{Activity Assays}

Enzyme activities were followed by kinetic analysis of the fluorescent signal of the hydrolysis product. The analysis was conducted in transparent non-binding 96 well plates (Greiner BioOne) using a Tecan (Infinite M200, Männnedorf, Switzerland) microplate reader. Plate reader parameters were optimized for each assay individually (gain, emission and excitation wavelength). First, the Michaelis-Menten kinetics were assessed to determine required substrate concentrations for maximum hydrolysis rates, $\mathrm{V}_{\max }$, as described in our previous work. ${ }^{[16]}$ Phosphatase activity was quantified by hydrolysis of 4-methylumbelliferyl phosphate (MUP, $0.1 \mathrm{mM}$ final concentration) to 4-methylumbelliferone. In each well $20 \mu \mathrm{L}$ MUP solution $(0.5 \mathrm{mM}$ in nanopure water) was added to $80 \mu \mathrm{L}$ experimental solution. After substrate addition, the plate was incubated at room temperature for $2 \mathrm{~min}$ (shaker $400 \mathrm{rpm}$ ) prior to measurements. Product formation was detected with $\lambda_{\text {ex }}$ of $360 \mathrm{~nm}$ and $\lambda_{\text {em }}$ of $475 \mathrm{~nm}$ every 2 min for at least 10 intervals. Aminopeptidase activity was quantified by the hydrolysis of L-leucine-7-amido-4-methylcoumarin (LeuC, $0.114 \mathrm{mM}$ final concentration) to 7-amino-4-methylcoumarin (AMC). In each well $20 \mu \mathrm{L}$ LeuC $(0.8 \mathrm{mM}$ in nanopure water) was added to $120 \mu \mathrm{L}$ sample and incubated at room temperature for $2 \mathrm{~min}$ (shaker $400 \mathrm{rpm}$ ). The product formation was detected with $\lambda_{\text {ex }}$ of $370 \mathrm{~nm}$ and $\lambda_{\text {em }}$ of $450 \mathrm{~nm}$ for at least 10 intervals. Product formation rates were calculated with linear regression model and quantified with an external calibration of the respective products.

\section{Analysis of Cyanopeptides}

Experimental solutions and cyanobacterial extracts were analyzed using a liquid chromatography high resolution mass spectrometer (LC-HRMS) system comprising: a CTC autosampler fitted with $20 \mu \mathrm{L}$ loop; a Dionex Ultimate 3000 RSLC liquid chromatograph; an Orbitrap Fusion Lumos mass spectrometer fitted with H-ESI source housing. Samples were injected at a volume of $20 \mu \mathrm{L}$ and cyanopeptides separated over an Xbridge $\mathrm{C} 18 \mathrm{LC}$ column (maintained at $30{ }^{\circ} \mathrm{C}$ ) using the following binary gradient elution program: 10:50:95:95:10:10\% mobile phase B at 0:4:17:25:25.1:29 min. Mobile phase A comprised 0.1\% v/v formic acid in Nanopure water, while mobile phase B comprised $0.1 \% \mathrm{v} / \mathrm{v}$ formic acid in methanol; each was degassed in an ultrasonic bath prior to use. Mobile phase flow rate was $0.2 \mathrm{~mL} \mathrm{~min}{ }^{-1}$ throughout.

Cyanopeptides were detected in the positive ionization mode using a data-dependent MS acquisition strategy. Herein, full scan data were acquired between 450 and $1 ' 350 \mathrm{~m} / \mathrm{z}$ at a resolution of 240'000 (full width-half maximum at $200 \mathrm{~m} / \mathrm{z}$; FWHM $200 \mathrm{~m} / \mathrm{z}$ ) with $1 \mathrm{e} 5 \mathrm{AGC}$ target, 40\% RF lens offset and 50ms injection time. Throughout the LC-MS acquisition procedure, MS source parameters were set to: 40 arbitrary units (AU) sheath gas; $10 \mathrm{AU}$ aux gas; $0 \mathrm{AU}$ sweep gas; $320^{\circ} \mathrm{C}$ ion transfer tube temperature; $40{ }^{\circ} \mathrm{C}$ vaporizer temperature and spray voltage of 3'500 V. Data-dependent high-resolution product ion spectra were obtained by HCD at $35 \%$ collision energy, at a resolving power of 17' 500 at $400 \mathrm{~m} / \mathrm{z}, 1$ e5 AGC target and maximal injection time of $80 \mathrm{~ms}$.

A target list of cyanopeptides was used for data analysis in Skyline (v4.1) including 712 cyanopeptides: 297 microcystins, 149 cyanopeptolins, 38 anabaenopeptins, 18 cyclamides, 61 microginins, 55 cryptophycins, 50 aeruginosins, and 44 other compounds. This suspect list included those cyanopeptides that were tentatively identified in previous extracts of the same biomass (Natumi, personal communication). Herein, those cyanopeptides were reported that could be identified based on exact mass ( $<5$ ppm mass error), accurate isotopic pattern (idotp $>0.9$ ), and evidence from the fragmentation data by diagnostic evidence. Calibration series between $1-500 \mathrm{ng} \mathrm{L}^{-1}$ were measured for available standards (microcystin mixture) and bioreagents (anabaenopeptin A and B, cyanopeptolin A and D, aerucyclamide $\mathrm{A})$.

Appropriate reference standards or even bioreagents are not available for the other cyanopeptides in these samples. Thus, the concentrations of tentatively identified cyanopeptides are reported in equivalent units of one of the available bioreagents or reference standard with the highest similarity in chemical composition (Supplementary Information: Table S2.4). Further data analysis was performed in Microsoft Excel (v16.26) and $\mathrm{R}$ (v3.5.2). Statistical analysis was performed in $\mathrm{R}$ and presented p-values correspond to two-sided t-test at $95 \%$ confidence level. 


\section{Results and Discussion}

\section{Extracellular Enzyme Inhibition by Cyanobacterial Extracts}

Extracellular enzymes have been exposed to a polar and an apolar fraction of extracts from cyanobacterial biomass of three different strains to determine potential inhibitory effects. A doseresponse behavior was apparent in the $M$. aeruginosa wild type and mutant extract with an onset of inhibition at concentration of $13 \mathrm{mg} \mathrm{L}^{-1}$ and $3.5 \mathrm{mg} \mathrm{L}^{-1}$ total cyanopeptides, respectively (Fig. 1A and B). An onset of inhibition by the P. rubescens extract was only observed in the apolar fraction after $24 \mathrm{~h}$ exposure to $0.2 \mathrm{mg} \mathrm{L}^{-1}$ total cyanopeptide concentration (Fig. 1C). The first aim was to assess whether enzyme inhibition occurs and the second aim was to identify cyanopeptides or peptide classes in the extracts that are potential candidates causing inhibition. Therefore, we compared changes in activity relative to different cyanobacterial metabolites.

\section{Inhibition by Metabolites from Microcystis aeruginosa}

Aminopeptidase was clearly inhibited by the exposure to cyanobacterial extracts (up to $18 \%$, Fig. 2A). Overall, the exposure to the apolar fractions for all cyanobacterial strains caused stronger inhibition compared to the respective polar fractions. These apolar fractions had higher inhibition potencies either because of higher inhibitor concentrations or more potent inhibitors. A final $5.5 \%$ inhibition of leucine aminopeptidase was observed by the polar fraction and significantly higher inhibition of $15 \%$ by the apolar fraction of the M. aeruginosa wild type extract (t-test, $\mathrm{p}=0.0113$ ). Also, significant inhibition was observed in the apolar fraction of the Microcystis mutant extract $(18 \%)$ but no inhibition could be detected by the respective polar fraction ( $t$-test, $\mathrm{p}=0.0025)$. To investigate whether certain cyanopeptides or peptide classes can be causing these effects, we compared the extent of inhibition with the cyanopeptide abundance. By processing the extract into a polar and apolar fraction, we achieved a quantitative separation of microcystins into the polar fraction of the wild type (>99\%) with the most abundant variants being microcystin-LR and its desmethylated form (Fig. 3 and Table S2.1). The Microcystis mutant is a knock-out mutant of one element of the gene cassette required to produce microcystins. As expected, this strain did not produce detectable concentrations of microcystins (Fig. 3). At first, the slight inhibition in the polar fraction of the wild type may hint towards inhibitory effects of microcystins present at $10.4 \mathrm{mg} \mathrm{L}^{-1}$. However, the differences of aminopeptidase inhibition by the polar fraction of the wild type and the mutant extract were not significant $(p=0.130)$. As the apolar fraction showed consistently higher inhibition of aminopeptidase, peptides in these fractions are potentially of higher concern. Both strains produced aerucyclamides and cyanopeptolins, which we could separate quantitatively into the apolar fraction for aercyclamides and to a high extent for cyanopeptolins. Thus, the cyanopeptolin concentrations in the apolar fractions were significantly higher in both strains (10.4 and $\left.4.1 \mathrm{mg} \mathrm{L}^{-1}\right)$ compared to the polar fraction $\left(2.4\right.$ and $\left.0.2 \mathrm{mg} \mathrm{L}^{-1}\right)$ and were dominated by the cyanopeptolin $\mathrm{A}, \mathrm{B}$ and $\mathrm{C}$ variants. Aerucyclamides were dominated by aerucyclamide $\mathrm{A}$ and $\mathrm{C}$ with total concentrations reaching $49.1 \mathrm{mg} \mathrm{L}^{-1}$ and $31.2 \mathrm{mg} \mathrm{L}^{-1}$ in the wild type and mutant, respectively. Based on these observations, we tentatively identified cyanopeptolins, aerucyclamides and to a minor extent microcystins as potential leucine aminopeptidase inhibitors produced by $M$. aeruginosa.

The same extracts showed no dose response for the phosphatase in the tested concentrations range (data not shown) but inhibition was apparent at highest doses. Neither fraction of the M. aeruginosa wild type extract showed inhibition of the alkaline phosphatase (Fig. 2B). Thus, microcystin-LR and its desmethylated form of $M$. aeruginosa cannot be suspected as potential

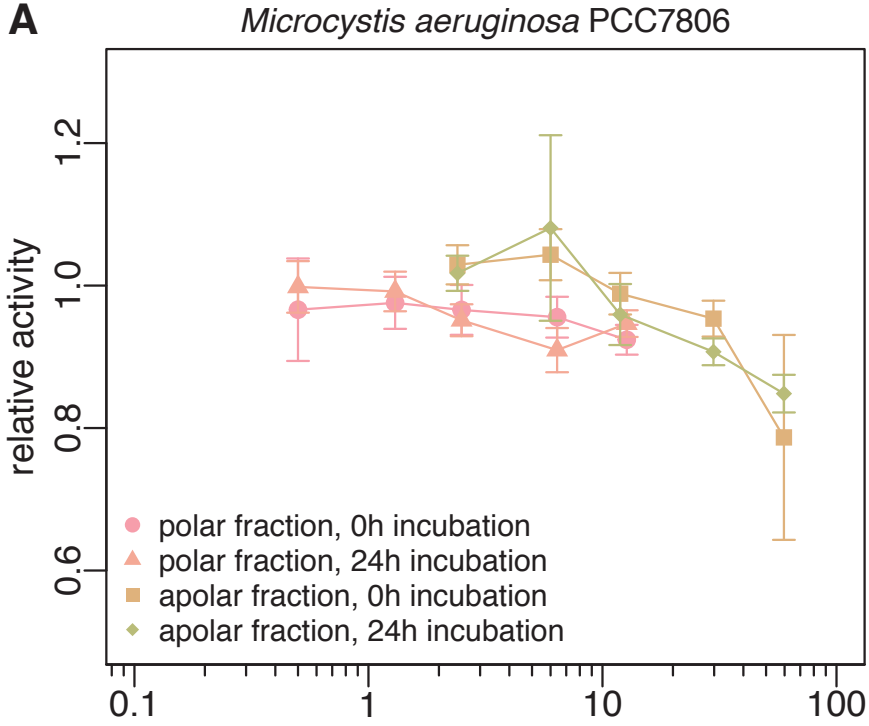

B Microcystis aeruginosa mutant

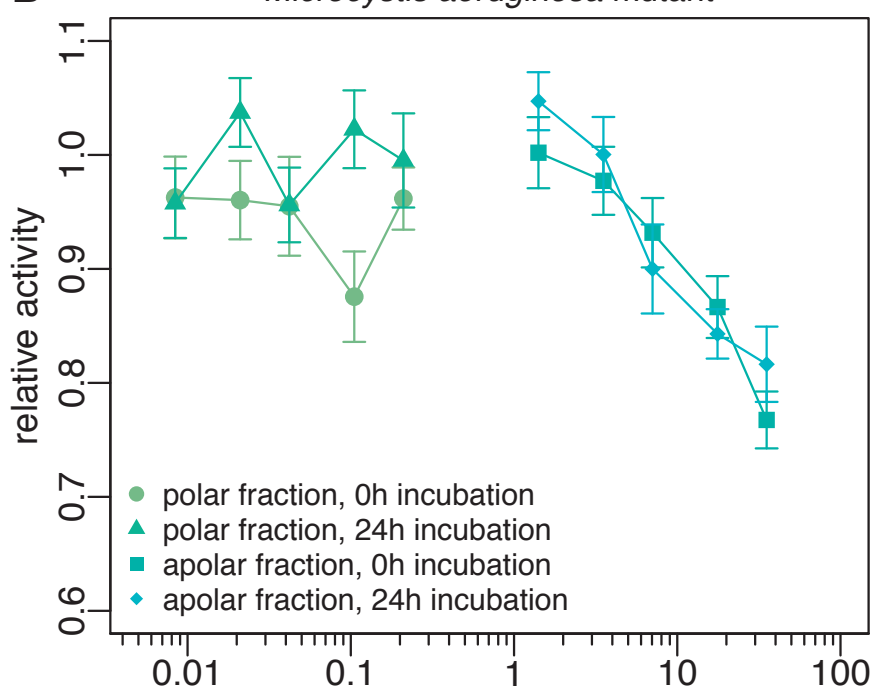

C Planktothrix rubescens

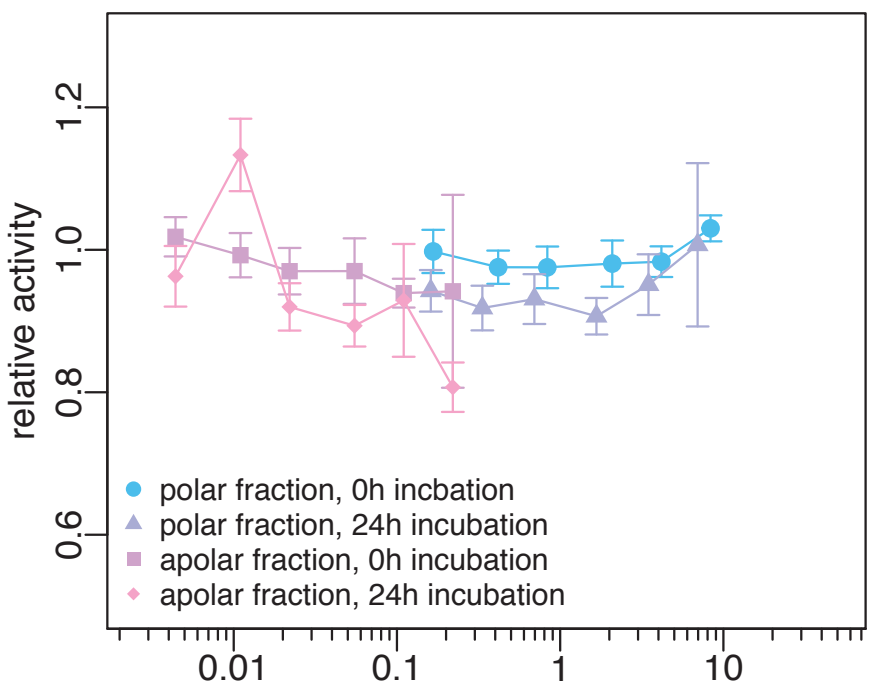

total cyanopeptide concentration $(\mathrm{mg} / \mathrm{L})$

Fig. 1. Relative aminopeptidase activities in presence of a dilution series of different extract fractions. Aminopeptidase was exposed to cyanopeptides extracted from A) Microcystis aeruginosa, B) Microcystis aeruginosa mutant, and C) Planktothrix rubescens. Enzymes were exposed to a polar (circles and triangles) and an apolar fraction (squares and diamonds) of the respective extract. Enzyme activity was measured after 30 to 60 mins exposure ( $0 \mathrm{~h}$, circles and squares) and after $24 \mathrm{~h} \mathrm{(24} \mathrm{h,}$ triangles and diamonds). 

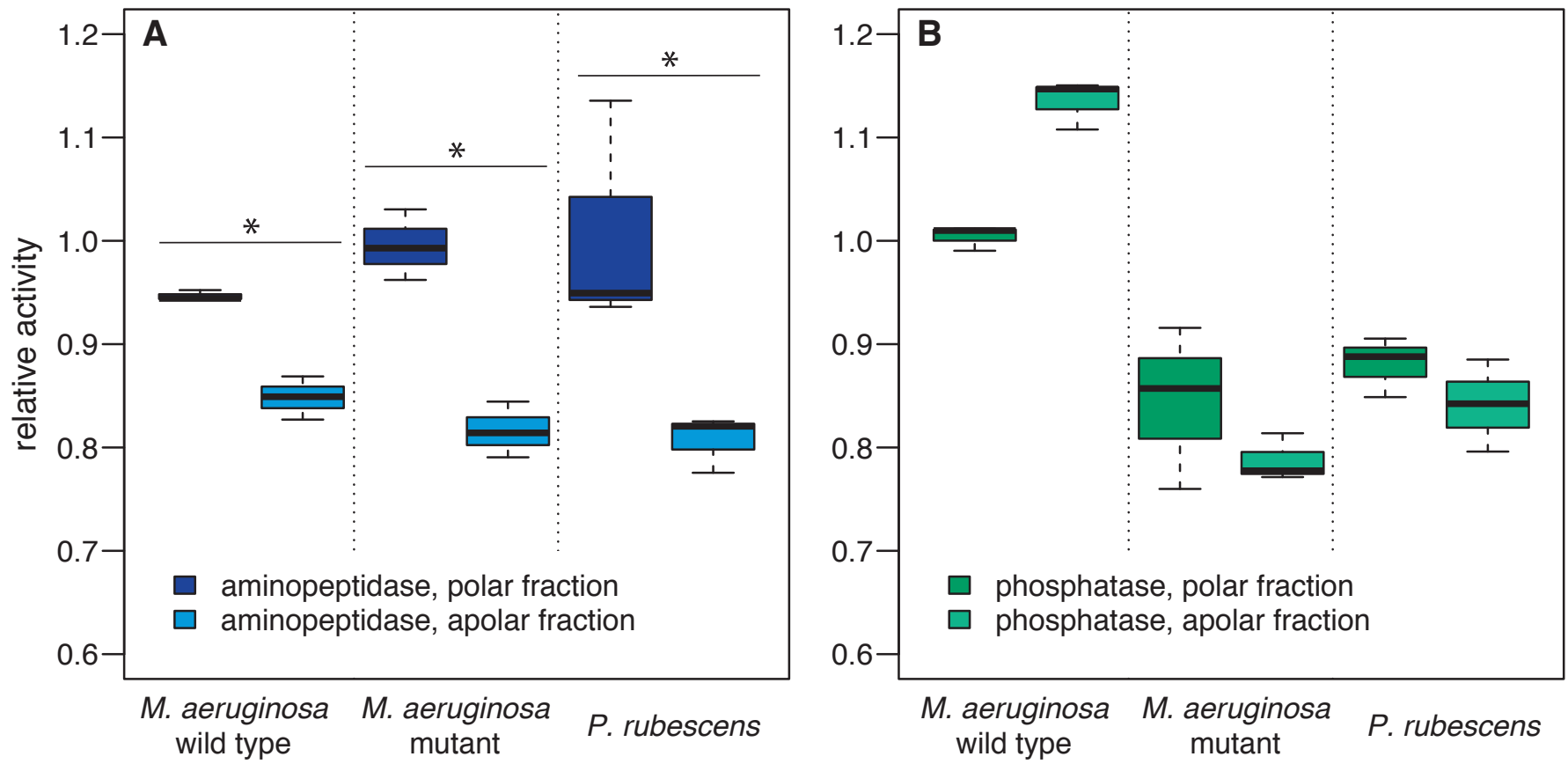

Fig. 2. Relative leucine aminopeptidase (A, blue) and alkaline phosphatase (B, green) activities after $24 \mathrm{~h}$ exposure to extracts of $M$. aeruginosa, a microcystin-free mutant of the same Microcystis strain or $P$. rubescens. Cyanopeptides were extracted from biomass of the respective strain in a polar (dark color) and an apolar fraction (light color). Enzymes were exposed to these two fractions separately. Activities are expressed relative to a control and measured in triplicates. Black bars in the boxplots represent the mean values and data in boxes with a star are significantly different (t-test, 95\% confidence level).
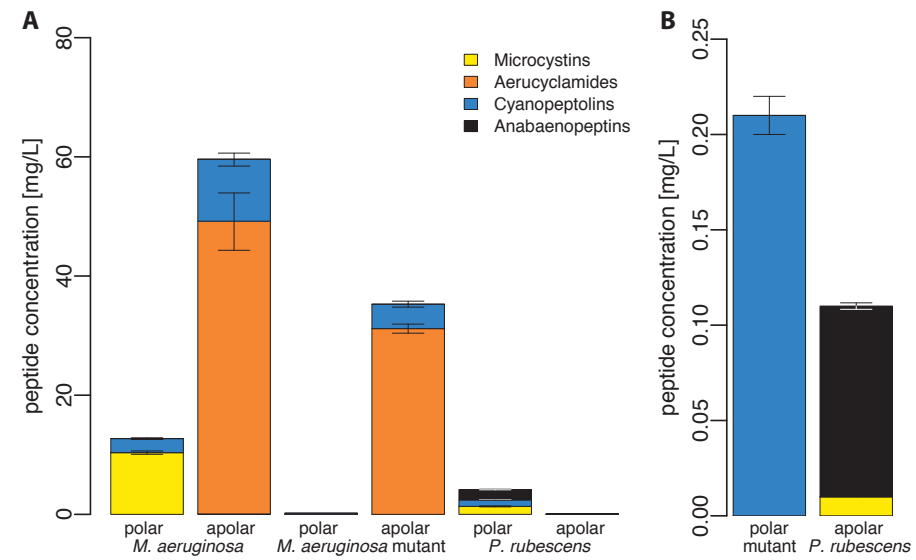

Fig. 3. A) Summarized cyanopeptide exposure concentrations in all extracts used in this work (extracts from $M$. aeruginosa, $M$. aeruginosa mutant, and $P$. rubescens, respectively). Concentrations are expressed as summarized concentration for each cyanopeptide class (aerucyclamides, anabaenopeptins, cyanopeptolins and microcystins). Tables S2.1, S2.2 and S2.3 show concentrations for the respective compounds in each class. B) Zoom in for extracts with low cyanopeptide concentrations. All concentrations were measured in triplicates.

inhibitors for alkaline phosphatase at the presented conditions. In contrast, exposure to extracts from the microcystin-free mutant led to phosphatase inhibition for both fractions with $16 \%$ and $21 \%$, respectively, which was not statistically significantly different. No significant difference in total cyanopeptide concentration nor the presence of individual compounds correlated with the different inhibition pattern for alkaline phosphatase between the wild type and mutant. These findings suggest that the observed phosphatase inhibition was rather caused by an additional metabolite not considered in our analysis. Both strains have the same genetic abilities for metabolite production other than the lack of microcystin production in the mutant. However, the expression of genes may be regulated differently, leading to different metabolomes.

\section{Inhibition by Metabolites from Planktothrix rubescens}

Exposure to extracts of $P$. rubescens caused inhibition of both enzymes, again, with an enhanced effect by the apolar fraction of $19 \%$ for leucine aminopeptidase and $16 \%$ for alkaline phosphatase (Fig. 2). Only alkaline phosphatase also showed inhibition by the polar fraction. Compared to M. aeruginosa, $P$. rubescens produced a different range of cyanopeptides. Within the microcystins and cyanopeptolins, different variants of these classes were produced. $P$. rubescens did not produce microcystin-LR but microcystin-RR-dehydro variants, which we could separate to a high extent $(99 \%)$ into the polar fraction of the extract. P. rubescens also produced more polar variants of cyanopeptolins dominated by micropeptin KR-998, which we could quantitatively separate into the polar fraction (100\%). While P. rubescens does not produce any aerucyclamides, it does produce anabaenopeptins that were also predominantly present in the polar fraction (94\%) and consisted mainly of anabaenopeptin A and B. Overall, the enzymes experienced much lower cyanopeptide exposure concentration from the $P$. rubescens extract with $4.2 \mathrm{mg} \mathrm{L}^{-1}$ and $0.1 \mathrm{mg} \mathrm{L}^{-1}$ for the polar and apolar fraction, respectively (Fig. 3). Yet, both fractions of $P$. rubescens inhibited alkaline phosphatase in a similar manner as the fraction from the $M$. aeruginosa mutant. The inhibition effect by the extract of $P$. rubescens on alkaline phosphatase is significant, but likely caused by either different metabolites or metabolites not considered in this study. Anabaenopeptins have been observed to inhibit tyrosine phosphatase, carboxypeptidases and human serine proteases. ${ }^{[9,23]}$ For leucine aminopeptidase, inhibition was only observed for the apolar extract of $P$. rubescens but metabolites other than anabaenopeptins must have been responsible.

\section{Enzyme Inhibition by Purified Cyanopeptides}

To disentangle the inhibition observed in experiments with complex extracts, we conducted a series of experiments with purified cyanopeptides. Based on our observation from the polar and apolar fraction of the cyanobacterial strains, we identified cyanopeptolins, microcystins and aerucyclamides as potential candidates causing inhibition. We selected cyanopeptide variants within these classes that 
were major constituents of the extracts and were available as purified reference standards or bioreagents $(>90 \%)$. We investigated a microcystin mixture containing equal concentrations of MC-LA, -LF, -LY, -LW, -RR, and -YR and nodularin and two single cyanopeptides; aerucyclamide A and cyanopeptolin A (Fig. 4).

\section{Microcystins}

Exposure tests with a microcystin mixture at $8 \mathrm{mg} \mathrm{L}^{-1}$ (i.e. $8.2 \mu \mathrm{M}$ ) led to $9.9 \%$ phosphatase and $31.1 \%$ aminopeptidase inhibition (Fig. 5). Concentrations of the microcystin mixture below $1 \mathrm{mg} \mathrm{L}^{-1}$ did not show significant inhibition (Fig. S4.1). We observed stronger inhibition for enzymes exposed to the microcystin mixture than the polar fraction of the wild type extract despite lower concentrations (10.4 $\mathrm{mg} \mathrm{L}^{-1}$ in the extract). However, the extract mainly consisted of microcystin-LR (Table S2.1) whereas the microcystin mixture contained only $1 \mathrm{mg} \mathrm{L}^{-1}$ microcystin-LR and seven additional variants at equal concentrations (MC-LA, $-\mathrm{LF}$, $-\mathrm{LY},-\mathrm{LW},-\mathrm{RR}$, and $-\mathrm{YR}$ and nodularin). Although microcystins are known to inhibit liver protein phosphatases (PP1 and PP2A) at low nanomolar concentrations, ${ }^{[7]} E$. coli alkaline phosphatase was only slightly inhibited at high concentrations of the microcystin mixture. These results are in line with previous observations when microcystin-LR did not inhibit six different phosphatase isoforms that are structurally unrelated to PP1 and PP2A. ${ }^{[24]}$ One of the tested phosphatases was a calf intestine alkaline phosphatase that is structurally related to $E$. coli alkaline phosphatase sharing approximately one third of its primary sequence (Fig. S5.1 for sequence alignment). Depending on the inhibition mechanism, enzymes that catalyze the same reaction and overlap in the sequence might also be inhibited by structurally similar inhibitors.

\section{Aerucyclamide A}

The exposure of phosphatase to up to $10 \mu \mathrm{M}$ of aerucyclamide A did not lead to enzyme inhibition (Figs 5 and S4.2). In contrast, aminopeptidase showed up to $29 \%$ inhibition when exposed to 10 $\mu \mathrm{M}$ aerucyclamide $\mathrm{A}\left(=5.3 \mathrm{mg} \mathrm{L}^{-1}\right)$. Aerucyclamide $\mathrm{A}$ was present in high concentrations in the apolar fractions of the Microcystis wild type and mutant extracts (Tables S2.1 and S2.3). These two fractions consisted mainly of aerucyclamides (82 and 88\%) with highest concentrations for aerucyclamide A ( 35 and $\left.11 \mathrm{mg} \mathrm{L}^{-1}\right)$. Despite the much higher aerucyclamide concentrations in the extracts, aminopeptidase was inhibited to a similar extent by the lower concentrated purified standard. We hypothesize that interactions of the apolar aerucyclamide with other extract components may reduce its interactions with the enzyme. Phosphatase was not inhibited by

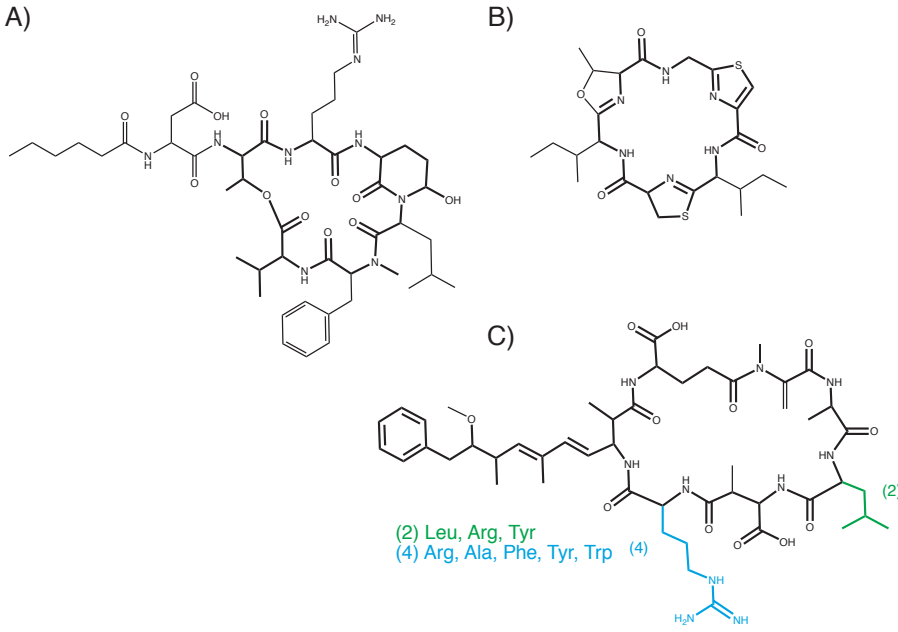

Fig. 4. Structures of A) cyanopeptolin A, B) aerucyclamide A and C) microcystin-LR. The microcystin mix additionally contained MC-LA, -LF, $\mathrm{LY},-\mathrm{LW},-\mathrm{RR}$, and $-\mathrm{YR}$ and nodularin. The addendum in the name refers to the amino acids present at positions 2 and 4 as listed in the figure. the purified aerucyclamide A, which supports the hypothesis that the strong inhibition by exposure to the apolar fraction of the mutant extract was caused by other metabolites. Aerucyclamide A has been found to be moderately cytotoxic against P388 murine leukemia cells ${ }^{[25]}$ and toxic against the model crustacean T. platyurus. ${ }^{[26]}$ These findings led to the hypothesis that aerucyclamide A might play an allelopathic role in ecosystems. The observed inhibition of extracellular aminopeptidase by purified aerucylamide A in this study indicates possible interference of metabolic functions.

\section{Cyanopeptolin A}

Exposure to cyanopeptolin A showed substantial reduction in aminopeptidase activity. Low inhibition around $16.2 \%$ was detected at up to $1 \mu \mathrm{M}\left(=0.96 \mathrm{mg} \mathrm{L}^{-1}\right)$ and a clear dose response was observed at higher concentrations with $18.7 \%$ at $5 \mu \mathrm{M}\left(=4.8 \mathrm{mg} \mathrm{L}^{-1}\right), 26.9 \%$ at $10 \mu \mathrm{M}\left(=9.6 \mathrm{mg} \mathrm{L}^{-1}\right), 30.9 \%$ at $25 \mu \mathrm{M}\left(=23.9 \mathrm{mg} \mathrm{L}^{-1}\right)$ and by $32.9 \%$ at $50 \mu \mathrm{M}\left(=47.9 \mathrm{mg} \mathrm{L}^{-1}\right)$ cyanopeptolin A (Figs 5 and S4.3). This general trend is in line with observed inhibition by the apolar fraction of cyanobacterial extracts both from the wild type and the mutant of $M$. aeruginosa with total cyanopeptolin concentrations of 6.0 and $5.3 \mathrm{mg} \mathrm{L}^{-1}$, respectively. Aminopeptidase inhibition by cyanopeptolins has been reported earlier when aminopeptidase $\mathrm{N}$ and cytosolic leucine aminopeptidase were inhibited by micropeptin SF909 (a cyanopeptolin) at half maximal inhibitory concentration (50\% inhibition, IC50) of around $5 \mu \mathrm{M} .{ }^{[27]}$ Here, no inhibition was observed for alkaline phosphatase, which supports the hypothesis that the observed inhibition by the extracts was caused by other metabolites.

\section{Conclusions}

Bacterial leucine aminopeptidase was strongly inhibited by cyanobacterial extracts, purified microcystins, aerucyclamide A and cyanopeptolin A. We observed aminopeptidase inhibition at low $\mathrm{mg} \mathrm{L}^{-1}$ concentrations of tested cyanopeptides, which corresponds to previously reported inhibitory concentration of different enzymes. ${ }^{[28]}$ Our data suggests a range of inhibitory potencies among the variants with the abundant microcystin-LR showing a comparably low response. Overall, we demonstrate considerable effects of secondary cyanobacterial metabolites on these ubiquitous hydrolytic enzymes. On the other hand, the concentrations typi-

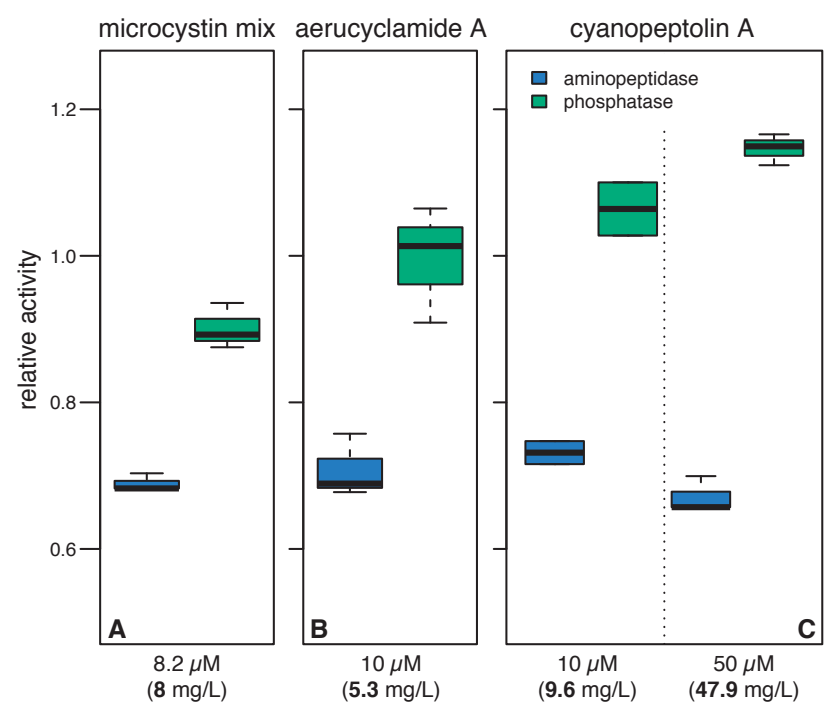

Fig. 5. Relative aminopeptidase (blue) and phosphatase (green) activities upon $24 \mathrm{~h}$ exposure to A) $8 \mathrm{mg} / \mathrm{L}$ microcystin mix, B) $10 \mu \mathrm{M}$ aerucyclamide A and C) $10 \mu \mathrm{M}$ or $50 \mu \mathrm{M}$ cyanopeptolin A. Activities were assayed between $8 \mu \mathrm{g} / \mathrm{L}-8 \mathrm{mg} / \mathrm{L}$ microcystin mix, $0.1 \mathrm{nM}-10 \mu \mathrm{M}$ aerucyclamide $A$ and $0.1 \mathrm{nM}-50 \mu \mathrm{M}$ cyanopeptolin $\mathrm{A}$. Exposure concentration are expressed in both $\mathrm{mg} / \mathrm{L}$ and $\mu \mathrm{M}$. Data for the whole assayed concentration ranges can be found in Figs S4.1 to S4.3. Activities are expressed relative to a control and were measured in triplicates. 
cally detected in these two dissolved phases during cyanobacterial bloom events can generally be expected to be one to three orders of magnitude lower compared to the concentration causing significant inhibition in the presented work. ${ }^{[1 b, 3]}$ Enzyme inhibition might not be significant for extracellular enzymes exposed to the bulk water. However, when aquatic organisms bioaccumulate cyanopeptides internal concentration may be reached that cause inhibition of their intracellular enzymes. Especially grazing species that (co-)feed on cyanobacterial biomass should be considered for further assessments. Toxicity towards grazers has been previously observed at LC50 values in the low micromolar range for microcystins, cyanopeptolins and aerucyclamides. ${ }^{[26,29]}$ While the underlying purpose why cyanobacteria produce these complex peptides is still unclear, researchers hypothesize that it is a defense against grazers. One mode of action to affect grazers would be to interfere with their metabolic functions and hence metabolically relevant enzymes. To our knowledge, these results demonstrate for the first time that cyanobacterial metabolites inhibit environmentally relevant enzymes. To further assess the complex interaction between cyanopeptides and extracellular enzymes additional purified cyanopeptides (e.g. different microcystin variants and anabaenopeptins) and other relevant enzymes (e.g. glycosidases, oxygenases, different isoforms and metabolic enzymes) need to be evaluated. A broader overview over a range of enzymes and metabolites will characterize the ecotoxicological risk of cyanopeptides on metabolic functions of aquatic organisms and biogeochemical cycles in bloom-affected waters.

\section{Acknowledgements}

We gratefully acknowledge funding support by the Swiss National Science Foundation (Grant number 200020-159809) and Marie Curie Innovative Training Network "Natural Toxins and Drinking Water Quality-From Source to Tap (NaToxAq)" (Grant No. 722493), and we thank Prof. Karl Gademann (University Zurich) for providing purified aerucyclamide $\mathrm{A}$.

\section{Supplementary Information}

Supplementary information is available on https://www.ingentaconnect.com/content/scs/chimia

Received: November 29, 2019

[1] a) T. R. Miller, S. L. Bartlett, C. A. Weirich, J. Hernandez, Environ. Sci Technol. 2019, 53, 5661, DOI: 10.1021/acs.est.9b00257; b) L. J. Beversdorf, A. Weirich Chelsea, R. Miller Todd, L. Bartlett Sarah, Toxins 2017, 9, 62, doi: 10.3390/toxins 9020062 .

[2] L. J. Beversdorf, K. Rude, C. A. Weirich, S. L. Bartlett, M. Seaman, C Kozik, P. Biese, T. Gosz, M. Suha, C. Stempa, C. Shaw, C. Hedman, J. J. Piatt, T. R. Miller, Water Res. 2018, 140, 280, DOI: https://doi.org/10.1016/j. watres.2018.04.032.

[3] E. M.-L. Janssen, Water Res. 2019, 151, 488, DOI: 10.1016/j.watres.2018.12.048

[4] a) J. H. Best, F. B. Eddy, G. A. Codd, Fish Physiol. Biochem. 2001, 24 171, DOI: 10.1023/A:1014081827372; b) T.-S. Dao, R. Ortiz-Rodriguez, L.-C. Do-Hong, C. Wiegand, Int. Rev. Hydrobiol. 2013, 98, 235, DOI: 10.1002/iroh.201301626; c) C. Keil, A. Forchert, J. Fastner, U. Szewzyk, W. Rotard, I. Chorus, R. Krätke, Water Res. 2002, 36, 2133, DOI: https:// doi.org/10.1016/S0043-1354(01)00417-1; d) F. D. Hulot, D. Carmignac, S. Legendre, C. Yéprémian, C. Bernard, Ann. Limnol. - Int. J. Lim. 2012, 48 , 337; e) K. Fernandes, A. Gomes, L. Calado, G. Yasui, D. Assis, T. Henry, A Fonseca, E. Pinto, Toxins 2019, 11, 220, DOI: 10.3390/toxins11040220.

[5] a) T.-S. Dao, R. Ortiz-Rodríguez, L.-C. Do-Hong, C. Wiegand, Int. Rev. Hydrobiol. 2013, 98, 235, DOI: 10.1002/iroh.201301626; b) M. Smutná, P. Babica, S. Jarque, K. Hilscherová, B. Maršálek, M. Haeba, L. Bláha, Toxicon 2014, 79, 11, DOI: https://doi.org/10.1016/j.toxicon.2013.12.009; c) M. Lürling, Limnol. Oceanogr. 2003, 48, 2214, DOI: 10.4319/ lo.2003.48.6.2214.

[6] a) R. E. Honkanen, J. Zwiller, R. E. Moore, S. L. Daily, B. S. Khatra, M. Dukelow, A. L. Boynton, J. Biol. Chem. 1990, 265, 19401; b) J. An, W. W. Carmichael, Toxicon 1994, 32, 1495, DOI: https://doi.org/10.1016/00410101(94)90308-5.

[7] J. Goldberg, H.-b. Huang, Y.-g. Kwon, P. Greengard, A. C. Nairn, J. Kuriyan, Nature 1995, 376, 745, DOI: 10.1038/376745a0.

[8] a) M. Kraft, C. Schleberger, J. Weckesser, G. E. Schulz, FEBS Lett. 2006, 580, 6943, DOI: https://doi.org/10.1016/j.febslet.2006.11.060; b) K. Ishida,
H. Matsuda, M. Murakami, K. Yamaguchi, Tetrahedron 1997, 53, 10281, DOI: https://doi.org/10.1016/S0040-4020(97)00684-4; c) K. Ishida, H. Matsuda, M. Murakami, Tetrahedron 1998, 54, 13475, DOI: https://doi. org/10.1016/S0040-4020(98)00826-6.

[9] S. Kodani, S. Suzuki, K. Ishida, M. Murakami, FEMS Microbiol. Lett. 1999, 178, 343, DOI: 10.1111/j.1574-6968.1999.tb08697.x.

[10] M. Murakami, S. Suzuki, Y. Itou, S. Kodani, K. Ishida, J. Nat. Prod. 2000, 63, 1280, DOI: $10.1021 / \mathrm{np} 000120 \mathrm{k}$.

[11] E. von Elert, L. Oberer, P. Merkel, T. Huhn, J. F. Blom, J. Nat. Prod. 2005, 68, 1324, DOI: 10.1021/np050079r.

[12] K. Gademann, C. Portmann, J. F. Blom, M. Zeder, F. Jüttner, J. Nat. Prod. 2010, 73, 980, DOI: $10.1021 / \mathrm{np} 900818 \mathrm{c}$.

[13] Y. Gao, J. C. Cornwell, D. Stoecker, K., M. S. Owens, Limnol. Oceanogr. 2014, 59, 959, DOI: 10.4319/1o.2014.59.3.0959.

[14] K. L. Cottingham, H. A. Ewing, M. L. Greer, C. C. Carey, K. C. Weathers, Ecosphere 2015, 6, DOI: 10.1890/ES14-00174.1.

[15] a) C. Arnosti, Annu. Rev. Mar. Sci. 2011, 401, DOI: 10.1146/annurevma-3-011111-200001; b) C. Arnosti, C. Bell, D. L. Moorhead, R. L. Sinsabaugh, A. D. Steen, M. Stromberger, M. Wallenstein, M. N. Weintraub, Biogeochemistry 2014, 117, 5, DOI: 10.1007/s10533-013-9906-5; c) R. M. Lehman, S. P. O'Connell, Appl. Environ. Microbiol. 2002, 68, 1569, DOI: 10.1128/AEM.68.4.1569-1575.2002; d) K. E. Davey, R. R. Kirby, C. M. Turley, A. J. Weightman, J. C. Fry, Deep Sea Res. Part II Top. Stud. Oceanogr. 2001, 48, 1003, DOI: https://doi.org/10.1016/S0967-0645(00)00106-5.

[16] C. M. Egli, E. M.-L. Janssen, Environ. Sci. Technol. 2018, 52, 7671, DOI: 10.1021/acs.est.7b06439.

[17] a) E. M.-L. Janssen, K. McNeill, Environ. Sci. Technol. 2015, 49, 889, DOI: 10.1021/es504211x; b) A. D. Steen, C. Arnosti, Mar. Chem. 2011, 123, 127, DOI: http://dx.doi.org/10.1016/j.marchem.2010.10.006; c) E. M. Espeland, R. G. Wetzel, Microb. Ecol. 2001, 42, 572, DOI: 10.1007/s00248-001-10237.

[18] D. Dziga, T. Goral, J. Bialczyk, Z. Lechowski, J. Phycol. 2009, 45, 1299, DOI: $10.1111 /$ j.1529-8817.2009.00742.x

[19] a) J. Vaitomaa, S. Repka, L. Saari, P. Tallberg, J. Horppila, K. Sivonen, Freshw. Biol. 2002, 47, 1582, DOI: 10.1046/j.1365-2427.2002.00901.x; b) J. Worm, M. Sondergaard, Aquat. Microb. Ecol. 1998, 14, 19; c) L. L. Kapustina, Microbiology 2006, 75, 606, DOI: 10.1134/S0026261706050110.

[20] C. Portmann, J. F. Blom, K. Gademann, F. Jüttner, J. Nat. Prod. 2008, 71, 1193, DOI: $10.1021 / \mathrm{np} 800118 \mathrm{~g}$.

[21] R. R. L. Guillard, C. J. Lorenzen, J. Phycol. 1972, 8, 10, DOI: 10.1111/ j.1529-8817.1972.tb03995.x.

[22] a) B. Druga, P. Turko, P. Spaak, F. Pomati, Environ. Sci. Technol. 2016, 50, 3416, DOI: 10.1021/acs.est.5b05973; b) E. Dittmann, B. A. Neilan, M. Erhard, H. Von Döhren, T. Börner, Mol. Microbiol. 1997, 26, 779, DOI: 10.1046/j.1365-2958.1997.6131982.x.

[23] a) M. Murakami, S. Suzuki, Y. Itou, S. Kodani, K. Ishida, J. Nat. Prod. 2000, 63, 1280, DOI: 10.1021/np000120k; b) T. Sano, K. Kaya, Tetrahedron Lett. 1995, 36, 5933, DOI: https://doi.org/10.1016/0040-4039(95)01198-Q.

[24] C. MacKintosh, K. A. Beattie, S. Klumpp, P. Cohen, G. A. Codd, FEBS Lett. 1990, 264, 187, DOI: 10.1016/0014-5793(90)80245-E.

[25] K. Ishida, H. Nakagawa, M. Murakami, J. Nat. Prod. 2000, 63, 1315, DOI: $10.1021 / \mathrm{np} 000159 \mathrm{p}$

[26] C. Portmann, J. F. Blom, K. Gademann, F. Jüttner, J. Nat. Prod. 2008, 71, 1193, DOI: $10.1021 / \mathrm{np} 800118 \mathrm{~g}$.

[27] S. Adiv, R. Aharonv-Nadborny, S. Carmeli, Tetrahedron 2010, 66, 7429, DOI: https://doi.org/10.1016/j.tet.2010.06.071.

[28] S. Adiv, R. Aharonv-Nadborny, S. Carmeli, Tetrahedron 2010, 66, 7429, DOI: https://doi.org/10.1016/j.tet.2010.06.071.

[29] L. J. Beversdorf, C. A. Weirich, S. L. Bartlett, T. R. Miller, Toxins 2017, 9, DOI: $10.3390 /$ toxins 9020062 .

[30] a) C. Portmann, J. F. Blom, M. Kaiser, R. Brun, F. Jüttner, K. Gademann, J. Nat. Prod. 2008, 71, 1891, DOI: 10.1021/np800409z; b) J. F. Blom, J. A. Robinson, F. Jüttner, Toxicon 2001, 39, 1923, DOI: https://doi.org/10.1016/ S0041-0101(01)00178-7; c) B. Bober, J. Bialczyk, J. Appl. Phycol. 2017, 29, 1355, DOI: 10.1007/s10811-017-1062-1; d) K. Gademann, C. Portmann, Curr. Org. Chem. 2008, 12, 326; e) E. Kohler, V. Grundler, D. Häussinger, R. Kurmayer, K. Gademann, J. Pernthaler, J. F. Blom, Harmful Algae 2014, 39, 154, DOI: https://doi.org/10.1016/j.hal.2014.07.003; f) M. Scherer, D. Bezold, K. Gademann, Angew. Chem. Int. Ed. 2016, 55, 9427, DOI: 10.1002/ anie. 201602755 .

\section{License and Terms}

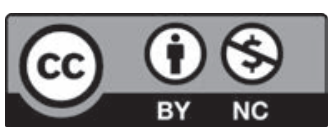

This is an Open Access article under the terms of the Creative Commons Attribution License CC BY_NC 4.0. The material may not be used for commercial purposes.

The license is subject to the CHIMIA terms and conditions: (http:// chimia.ch/component/sppagebuilder/?view=page\&id=12).

The definitive version of this article is the electronic one that can be found at doi:10.2533/chimia.2020.122 